\title{
Enterprises' perception and practice of humane entrepreneurship
}

\author{
Anna Dębicka, Karolina Olejniczak and Joanna Skąpska \\ Department of Entrepreneurship and Business Communication, \\ Poznan University of Technology, Poznan, Poland
}

\begin{abstract}
Purpose - As a new concept for humane entrepreneurship (HumEnt) evolves, many new research questions arise. At the exploratory stage, the authors found it relevant to examine and discuss the perception of the fundamental assumptions of the HumEnt concept and activities undertaken in this area by business practice. Design/methodology/approach - To thoroughly understand the studied phenomenon, a combination of quantitative and qualitative methods was used. An exploratory survey was obtained from 126 purposefully selected enterprises in Poland; then, a single case study was analysed.

Findings - The conducted analysis showed differences between the activities of enterprises and the perception of the HumEnt concept among employees that are especially noticeable at different levels of the management hierarchy.

Research limitations/implications - The multifaceted nature of the results obtained is limited by the inability to infer international differences, to capture trends over time and to generalise to the total population of enterprises.

Practical implications - Although the surveyed companies recognise the importance of the HumEnt concept, it is not tantamount to its execution. The research results may be valuable, especially for smaller enterprises, where the business practice may require support in applying the HumEnt approach.

Originality/value - The research explored both the actual state confirmed by the actions taken and the perception of the importance of individual elements of HumEnt. A knowing-doing gap has been demonstrated between these planes. Moreover, thanks to a two-stage study, practices were selected that can be successfully implemented also in small and medium-sized enterprises.
\end{abstract}

Keywords HumEnt, SMEs, Human cycle, Sustainability

Paper type Research paper

\section{Introduction}

The dynamics of changes in the contemporary global economy require a new look at the phenomenon of traditional entrepreneurship. The year 2020 and the coronavirus disease (COVID-19) outbreak forced organisations of all kinds to adjust to the changing needs of their people, customers and stakeholders. While navigating financial and operational challenges, emphasised in most existing entrepreneurship theories, the organisational purpose has taken on heightened significance, and the agenda has moved from traditional, profit-driven models to include a broad range of social values. In the VUCA environment (volatility, uncertainty, complexity, ambiguity), social responsibility, inequality, inclusion, income distribution, climate change and environmental sustainability have become part of the leadership manifesto.

\footnotetext{
(C) Anna Dębicka, Karolina Olejniczak and Joanna Skąpska. Published by Emerald Publishing Limited. This article is published under the Creative Commons Attribution (CC BY 4.0) licence. Anyone may reproduce, distribute, translate and create derivative works of this article (for both commercial and noncommercial purposes), subject to full attribution to the original publication and authors. The full terms of this licence may be seen at http://creativecommons.org/licences/by/4.0/legalcode

The authors would like to thank Journal of Small Business and Enterprise Development Editor Eric Liguori and two anonymous reviewers for their highly constructive feedback that allowed them to improve the manuscript.
}

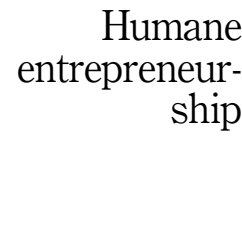

Received 22 January 2021 Revised 16 August 2021 Accepted 23 August 2021 
JSBED

29,1

128

Both the situation related to the COVID-19 pandemic and the entire set of new legal acts regulating the epidemiological situation in the world, also in Poland, results in a series of socio-economic changes. These changes include a decrease in the sense of well-being, a decrease in motivation, a decrease in employees' involvement, employment rationalisation, changes in the needs of employees in connection with new forms of work organisation, new opportunities and development chances and new support programmes for the implementation of development projects, including those in the field of research and development (R\&D) (Tuzovic and Kabadayi, 2020; Bartsch et al., 2020; Braverman, 2020). The ongoing changes in the environment force enterprises to look for new solutions, which are often associated with changing employees' needs to improve competencies, change their attitudes, implement new forms of motivation, and many others (Aguinis et al., 2020). Additionally, the current situation may further affect the level of employee engagement (Chanana, 2020; Kumar, 2021), which as Kim et al. (2021) point out, is a significant problem for many economies.

Therefore, the 2030 Agenda for Sustainable Development, an action plan for people, the planet and prosperity, becomes even more important. In reference to the 2030 agenda, a declaration was created to support entrepreneurs and small enterprises, which significantly emphasises the importance of this group in achieving goals for sustainable development. In particular, it is about creating efficient and high-quality jobs while at the same time taking care of the quality of ecosystems and the interests of local communities.

Given these circumstances, scholars recently began to conceptualise a novel approach that argues that traditional entrepreneurship should be enhanced by adding a human element described as humane entrepreneurship (HumEnt) (Bae et al., 2018; Parente and Kim, 2021). Moreover, Parente et al. (2018) identified entrepreneurship and enterprises as one of the best radical engines for social change.

The concept of a human approach to entrepreneurship is the answer to such defined needs of modern enterprises and is based on entrepreneurial orientation, leadership and fair human resources management. In this way, the HumEnt concept becomes a postulate that proposes creating prosperity both in the financial and human dimension while respecting the principles of social and ecological sustainable development (Parente et al., 2018).

As the HumEnt concept is relatively new and in the early stage of development, it requires in-depth research, both quantitative, which would show specific trends, and qualitative, allowing for an in-depth understanding of the phenomenon and discovering what the results of quantitative research may indicate. As many scholars point out, future research should develop and validate the measurement scale for HumEnt. In particular, this refers to the measure of humane resource orientation (HRO). Recalling the words of Parente et al. (2020, p. 524) "one way to assess HRO from a strategic posture perspective is to pay attention to humane resource practice in terms of the actions taken to strategically pursue given practices. Unfortunately, an accepted measurement scale of entrepreneur/top manager behavior fitting $\mathrm{HRO}$ as intended in the domain of HumEnt does not exist" it seems accurate recognition of this phenomenon in-depth, both in the context of the attitudes and behaviour of business practitioners.

It seems particularly valuable to examine whether and what trends related to the implementation of this concept can be noticed. Following this goal, this paper aims first to analyse, in how many enterprises the importance of individual assumptions of the HumEnt concept can be noticed, in how many enterprises actions suggesting the implementation of this concept can be observed and what are specific characteristics of these enterprises. Second, based on our research results, we use the single case study method to get to know the circumstances and understand the phenomenon's nature and context. We identify activities of an enterprise, which is characterised by a high implementation of the HumEnt concept. In order to achieve the research goals, we formulated the following research question: what is 
the perception and practice of the HumEnt concept in Polish enterprises and what activities characterise an enterprise with a high degree of its implementation. Finally, we formulate good practices in implementing the most fundamental assumptions of the HumEnt concept, which can provide valuable guidance for business practitioners.

The article consists of three parts. First, we focused on the literature review of the HumEnt foundations and its components. Then, based on the cited conceptual models, we presented the construction of our research method, research sample and findings, and research results. In the third part, we discussed the obtained results, further research areas and practical application values of our work.

\section{Literature review of the humane entrepreneurship foundations}

Global development, competition and the socio-economic climate force enterprises to seek new development opportunities and qualitative changes. Empirical research in this area indicates the social, cultural and environmental costs of economic growth. Therefore, organisations are increasingly oriented towards the postulates of sustainable development to ensure future generations' ability to meet their own needs (Rosati and Faria, 2019; Szabowska-Walaszczyk et al., 2013).

In 2015, the United Nations (UN) issued a document entitled "Transforming our world: the 2030 agenda for sustainable development". The document announced 17 Sustainable Development Goals (SDGs) and 169 specific goals. It deals with sustainable development issues, including poverty, hunger, health, well-being and education. The document's significance lies in the fact that, for the first time, a comprehensive programme has been agreed upon that can stimulate actions for sustainable economic, environmental and social development (UN General Assembly, 2015). The 17 SDGs are intended to serve as a common standard involving actors at all levels, including governments, civil society and the private sector (Gusmão Caiado et al., 2018; Ntona and Morgera, 2018; Recuero Virto, 2018). It can even be concluded that there has never been such an intense debate on the role and importance of business in society and for society. There has never been such tremendous pressure before on corporations to contribute to the world's sustainable development. This trend applies to almost the entire world, although the scale of this phenomenon differs depending on the country and region of the world. Many government and non-governmental organisations (NGOs) believe that issues related to sustainable development are related to entrepreneurial patterns (Beltz and Binder, 2017). The need to promote the principles of sustainable development, which combines the interests of both the business and community, is growing internationally and occupying an increasingly high place on governments' political agendas (Parente et al., 2018).

The new theory of HumEnt, as indicated by Parente et al. (2018), integrates three different concepts in an entrepreneurial strategic posture (ESP): entrepreneurial orientation (EO), sustainable development orientation (SDO) and human resource orientation (HO). As the authors further suggest, the theory of HumEnt can be seen as an extension of previous research but with a new model to consider. The HumEnt theory can help by meeting the challenges of creating a more sustainable world (Parente et al., 2018). In addition, as the digital transformation progresses and industry boundaries fall, it is gaining importance from the point of view of business management to understand customer needs, develop employee skills and increase business partner opportunities. HumEnt can play a key role in the development of business ecosystems and thus in economic growth. The study by Kim et al. (2018a) shows that HumEnt does not directly contribute to a healthy business ecosystem, but that sustainable HumEnt and business system opportunities have a positive relationship with gross domestic product (GDP) growth.

Since so far there has been a lack of one universally accepted theory of sustainable entrepreneurship, another theoretical basis of HumEnt is the corporate social responsibility 
JSBED

29,1

(CSR) theory (McWilliams and Siegel, 2001). The CSR is related to sustainable entrepreneurship, but is also more general. The CSR theory also has more established theoretical traditions than sustainable entrepreneurship in the field of sustainable development. Due to the development of research in this field, it has gained popularity over time. The CSR theory can contribute to the HumEnt of enterprises, as it encompasses various organisational activities and policies undertaken by enterprises to meet the expectations of multiple stakeholders (Parente et al., 2018).

Porter and Kramer (2011) proposed the concept of creating shared value (CSV), according to which corporations can increase their economic competitiveness, and society can benefit at the same time. The authors suggested the need for a higher form of capitalism in which the generation of profits occurs in conjunction with social goals. This concept emphasises the limitations of current business strategies driven by shareholder-oriented pressure and emphasises delivering financial results in the short term. By highlighting the problem of the identity and legitimacy of current businesses and capitalism, CSV draws attention to the idea of twin values-business and social benefits realised at the same time (Kim, 2018).

The study by Park (2020) among Korean companies listed on Korea composite stock price index (KOSPI) aimed to investigate the mutually beneficial relationship between CSV and CSR activities and their impact on productive behaviour through involvement in work. The study shows that commitment and organisational citizenship behaviour (OCB) play an important role in the relationship between CSV and CSR activities and the performance of an organisation.

The interest of researchers in the subject of shared value strategies (SVSs) is constantly growing. However, the studies conducted so far do not answer what conditions an enterprise must meet to implement SVSs successfully. Mühlbacher and Böbel (2019) aimed to fill this gap by gathering evidence on successful SVSs, stakeholder management, CSR and positive social change. The authors proposed five complex conditions necessary for successful SVS implementation: shared value-oriented entrepreneurial vision, strategic alignment (STA), shared value-oriented innovation (SVI), networking capabilities (NCs) and impact monitoring. In addition, the authors suggested a few simple conditions that make up the complex conditions aimed at changing the orientation of companies from zero-sum strategies to SVS systems in which everyone can win.

There is also no consensus among entrepreneurship researchers as to the dimensions of EO. While many embraced the EO conceptualisation of Miller's three dimensions (1983): innovation, proactivity and risk-taking, Covin and Slevin (1989) tested another fourth dimension: competitive aggressiveness. Lumpkin and Dess (1996), in turn, suggested a fifth dimension, which is autonomy. Contrary to Covin and Slevin, Lumpkin and Dess (1996) also argued that the dimensions of EO might vary depending on the specifics of the context. Although there is disagreement among the authors as to the dimensions characterising EO, it can be assumed that this conceptualisation is useful to evaluate HumEnt, since it represents enterprises operating in a dynamic environment, in the growth phase and operating in mature industries (Parente et al., 2018).

Driven by a resource approach, a Tanzanian survey of 300 small and medium-sized enterprises (SME) owner-managers from the welding industry located in Dar es Salaam, Mbeya and Morogoro Municipal Centres aimed to determine the impact of entrepreneurial orientation on SME performance through competitive advantage. Entrepreneurial orientation was taken as an intangible resource in the form of processes. The study used the research method with the cross-sectional design using the AMOS statistical software. The results of this study indicated that competitive advantage mediates the relationship between entrepreneurial orientation and SME performance. The results of the study suggest that the resource-based view is appropriate not only to describe physical resources but also intangible resources such as entrepreneurial orientation (Kiyabo and Isaga, 2020). 
Of the three components of HumEnt, human resource orientation (HRO) is the least discussed strategic attitude. The HumEnt premise is that companies can generate higher profits while respecting employees and creating conditions for enjoying work. This component is understood as strengthening the position of employees and managers in the company by striving for their greater involvement. Although this area is not clearly defined, its definitions indicate commitment, passion in performing professional duties, enthusiastic attitudes and energy in action (Parente et al., 2018).

\section{Components of humane entrepreneurship}

As an extension of previous, traditional research that focuses on connections between societal and economic progress, HumEnt is composed of two dimensions, the human and enterprise cycle (Bae et al., 2018).

Bae et al. (2018) determined that there are five factors describing each cycle that contribute to value creation. Elements of the enterprise cycle - envisioning, enthusiasm, experimentation, enlightenment and excellence - appear in previous studies, and are considered by the scholars as a foundation of traditional entrepreneurship theory. On the other hand, the human cycle focuses on social dynamics and consists of components such as empowerment, ethics, equality, engagement and ecosystem.

First, empowerment is encapsulated with the firm's vision of purpose that employees intertwine their beliefs with, shape and build a culture that unites them and an entrepreneur around a common cause. From the psychological perspective, empowerment is seen as a process where people develop skills to become independent problem-solvers and decisionmakers. In addition, Menon emphasises the business context of this generic construct that involves "moving decision-making authority down the (traditional) organisational hierarchy" (Menon, 2001, p. 156). Consequently, in the HumEnt environment, empowerment boosts people's productivity through such measures as profit or return on assets.

The definition of ethics, the second component of the human cycle, described by Brown et al. (2005, p. 120), emphasises "the demonstration of normatively appropriate conduct through personal actions and interpersonal relationships, and the promotion of such conduct to followers through two-way communication, reinforcement, and decision-making". According to Eisenbeiß and Giessner (2012), this element consists of eight virtues: (1) clarity - which in the entrepreneur context means concrete and feasible directions in regard to ethical leadership, and supports ethical decision-making; (2) congruency of management; (3) congruency of the supervisor - stresses the leading by example approach to ensure an ethical business; (4) feasibility - focuses on the ethical aspects of organisational resources, such as time, finances, equipment, information and personal authority; (5) supportability - refers to a shared commitment to ethical behaviours and social responsibility that manifests itself in fair treatment, environmental aspects, honesty and integrity; (6) transparency - means visibility in an organisation that refers to actions undertaken by both an entrepreneur and employees and their consequences; (7) discuss ability - assumes open discussions about ethical and unethical behaviours and issues; (8) sanction ability - awareness of consequences of both ethical and unethical behaviours. From the economic and profit-based perspective, unethical behaviours have a direct impact on firms at all stages of development and result in ineffective job performance, absenteeism, and unsafe behaviour and additionally less common forms such as violence, theft, substance abuse, and sexual harassment (Jex and Britt, 2008), which in turns leads to decreases in organisational performance, financial losses, reputational damage, safety concerns and a loss of customers.

Equality, the third element of the human cycle described by Bae et al. (2018), means by definition of the Cambridge Dictionary "the right of different groups of people to have a similar social position and receive the same treatment". In the context of $\mathrm{HO}$, the term equity 
JSBED

29,1

132

may also be encountered (Kim et al., 2018a; Pfeffer and Jeffrey, 1998). Notwithstanding, the authors of this paper suggest using equality and equity independently as the equality expressed in the democratic ideals of social justice demands equality of results (Strike, 1985). In some cases, equity means equal shares, but in other cases, it can mean shares determined by need, effort expended, ability to pay, results achieved, ascription to any group (Blanchard, 1986) or by resources and opportunities available (Larkin and Staton, 2001). From the business management perspective, equality occurs when all employees feel that they are being valued equally, while equity comes when all members of a diverse population of employees have equal opportunities and support to develop, grow and succeed. Nevertheless, the concept of fairness, constituting the essence of both terms, is a source of creativity and innovation within an organisation; it has an impact on employee performance outcomes with reductions in absenteeism, labour turnover, improved employee relations and undeniably is the core value of HumEnt.

Engagement, the fourth element of the human cycle, indicates the relationship between a person and performed work, including the organisational context (Schaufeli and Bakker, 2010). From the economic point of view, (1) engagement is one of the most important wellbeing indicators (Csikszentmihalyi, 1990), (2) employee engagement predicts employee turnover and customer loyalty (Harter et al., 2002), (3) psychological well-being of workers predicts, to some extent, their productivity (Donald et al., 2005). Previous studies have established determinants that there is a correlation between employee engagement and positive business results. Bakker (2011) indicates that positive emotions caused by this component of the human cycle allow for greater thought-action repertoire, have an impact on better health of employees, which results in their dedication to work and evokes more significant collaborative effort.

The last element of the human cycle is an ecosystem. An ecosystem is broadly defined as "a purposeful collaborating network of dynamic interacting systems that have an everchanging set of dependencies within a given context" (Sussan and Acs, 2017, p. 57). An entrepreneurial ecosystem through a holistic collaborative approach tackles challenges around finance, talents, socio-cultural, economic and political factors, infrastructure, markets, and policy, and is considered as an important factor in building resilient economies.

\section{Research scheme}

In this work, which is supposed to consider how the concept of HumEnt by Polish enterprises is implemented, for qualitative evidence, we developed a research scheme consisting of two stages. We set main research goals as follows: (1) examining the actual state of the implementation of the selected HumEnt components-focussing on human cycle competences, (2) examining the relationship between these components and the characteristics of the studied enterprises, (3) capturing the possible knowing-doing gap between the actual state and the perception of the importance of individual components of HumEnt, (4) checking what specific activities are undertaken in an enterprise with a high level of implementation of the assumptions of the HumEnt theory. The research scheme is shown in Table 1.

\begin{tabular}{lll}
\hline Study & Goals & Research method \\
\hline 1 & Actual state and perception & Enterprises CAWI $(n=126)$ \\
& Knowing-doing gap & Statistical analysis \\
2 & Best practices & Employee survey $(n=47)$ \\
& In-depth-interview
\end{tabular}

Table 1.

The research scheme 
The combination of quantitative research with qualitative research aimed to obtain a synergy effect that may contribute to a better understanding of the studied phenomenon. Considering that the HumEnt theory is still under development, and the measurement scales for HumEnt have not yet been developed and validated (Parente et al., 2020), it seems that getting to know the real-life context may be a good starting point for further research in this area.

First, we conducted a study among enterprises of all sizes regarding the perception of the HumEnt components and undertaking specific activities related to them (actual state). Then, the collected data were subjected to statistical analysis. In the next step, based on the data obtained in the first step, we chose a company characterised by a high level of perception of the significance of HumEnt and a high degree of implementation of specific activities in this area. Finally, through the use of an in-depth interview in this company, we selected good practices proving high perception and awareness of the implementation of the assumptions of this concept.

\section{Data and methods}

The study was conducted using a computer-assisted web interview (CAWI) among small, medium, and large enterprises. The chosen method is based on completing the respondent questionnaire that is published on a dedicated website instead of the traditional paper form. In research conducted using the CAWI method, the respondents, by definition, can only be individuals who have access to the Internet (Couper, 2000; Ebert et al., 2018). Therefore, this method is suitable for groups with a high rate of Internet access. This group includes, among others, enterprises of all sizes, most of which $(98 \%)$ in Poland have access to broadband Internet (Statistics Poland, 2020).

According to the definition which has been in force in the European Union since 2005 (EC Recommendation, 2003, p. 5):

the category of micro, small and medium-sized enterprises (SMEs) is made up of enterprises which employ fewer than 250 persons and which have an annual turnover not exceeding EUR 50 million, and/or an annual balance sheet total not exceeding EUR 43 million.

On the other hand, the employment threshold for SMEs in the USA is fewer than 500 employees (US International Trade Commission, 2010), which means that it is much higher than that applied in the European Union (EU). As the definition of SMEs may differ depending on the region, the authors decided that the main criterion for data extraction will be (1) micro and small enterprises up to 49 employees, (2) medium-sized enterprises from 50 to 249 employees, and (3) those with more than 249 employees in order to identify the relationship between the studied enterprises and their characteristics.

In the initial phase of the analyses, all qualitative parameters were characterised by presenting the number $(n)$ and percentage $(\%)$ of individual items, and the answers were then subjected to the coding procedure. The next stage of the research consisted in assigning numerical values to the selected responses with the perception of HumEnt.

The chi-square test $\left(\chi^{2}\right)$ was used to determine the differences between the compared groups. Being aware of the ongoing $p$-value debate and its importance in revealing the significance of a relationship or effect (Maula and Wouter, 2020; Lakens, 2021), we decided to present its value, which may still be of practical importance (Di Leo and Sardanelli, 2020). Therefore, the following terms were used to determine the significance level of the identified relationships or differences ( $p$ values): $p \geq 0.05$ as a statistically nonsignificant value and $p<0.05$ as a statistically significant value.

A binary logistic regression analysis with a zero-one code was performed to assess the probability of selected characteristics in the surveyed enterprises. The modelled dependent 
JSBED

29,1

134

variable was set to one, which means the implementation of selected activities within the examined component. All statistical analyses were conducted using STATISTICA 13.3 (TIBCO Software Inc.) for the Windows Version.

In order to select an enterprise for an in-depth analysis, an assessment of the enterprises that took part in the survey was carried out. In addition to the surveys, business websites, and archival materials, such as press articles and materials posted on social media, were analysed. The in-depth interview was conducted face-to-face with the manager; all answers to questions were recorded and digitised. In order to obtain all the necessary data and information and be able to use them in the study, we had to maintain the anonymity of the surveyed companies.

\section{Questionnaire construction}

As the study concerns a new concept, and at the time of the study, there were no fully developed and verified measures of HumEnt, we decided to create an exploratory survey questionnaire. The questionnaire was divided into three main parts. The first part contained questions concerning the characteristics of the enterprises, including the size of employment, market and business profile. The next part contained questions about the actual state of the selected components of HumEnt in a given enterprise. According to the measures of HumEnt proposed by Bae et al. (2018) and Kim (White Book, 2016), the components corresponded to a specific item in the questionnaire: Four for the human dimension (equality, ethics, engagement, and empowerment) and five for the enterprise dimension (enlightenment, enthusiasm, experimentation, envisioning and excellence). At this stage of the research, due to the lack of consensus among researchers on measuring the component ecosystem, we decided to omit this area of the human cycle. The items in that part of the questionnaire were formulated in such a way as to check whether a given company conducts particular activities in a given area. Therefore, the surveyed companies were directly asked whether they conduct any activities that would suggest executing the HumEnt concept in the indicated areas as part of their business activities. The last part of the questionnaire concerned assessing each of the ten components of HumEnt in terms of the importance from the perspective of the respondents' enterprise to indicate the perceptions of respondents in this area. In order to measure the selected items, a five-point Likert scale was used (very low, low, neutral, high, very high).

The second study was conducted on the basis of a semi-structured in-depth interview with a manager, in which the questions concerning the description of specific activities undertaken by the enterprise were used. In addition, we examined the perception of individual elements of the HumEnt concept among employees. They were divided into two groups: managers and lower-level workers. We wanted to see if differences are depending on the level in the organisational structure.

STUDY 1: The actual state and the perception of the surveyed enterprises related to the assumptions of the HumEnt concept. Sample. The research was conducted using categorised interviews among enterprises of all sizes in Poland, the Greater Poland region. Purposive sampling was used in the studies. The survey was made available to a local networking group associating enterprises that share their experience and good practices regarding human resources management, innovations and tools. During the exploratory survey, data were collected from 126 respondents. The authors' intention was not to infer from the sample to the general population in statistical terms but to best reflect the phenomena (Maxwell, 2010, 2014).

The distribution of enterprises in terms of size is presented in Table 2.

Results. The implementation of selected activities in the dimension of the enterprise cycle in the surveyed enterprises is presented in Table 3 . The statistical analyses showed significant differences between the size of the enterprise and the activities in the field of empowerment 
$(\phi=0.0038)$, ethics $(\phi \leq 0.0001)$, equality/equity $(\phi=0.0073)$ and engagement $(\phi=0.0004)$. Moreover, statistically significant differences were also observed between activities performed and markets in which the surveyed enterprises operated. Tables 4 and 5, based on binary logistic regression, show the probability of the occurrence of activities concerning the selected components of the human cycle, depending on the characteristics of the surveyed enterprises.

The following results refer to the perceptions of the respondents regarding the selected HumEnt components. The correlation matrix of Spearman's rank variables for the selected HumEnt components is presented in Table 6.

In order to test the reliability of the measures used in the study, Cronbach's alpha test was carried out. The Cronbach's alpha was 0.922 for both the human and enterprise cycles measures. Referring to Bland and Altman (1997), alpha values ranging from 0.7 to 0.8 can be considered satisfactory, while those above 0.9 have an application dimension.

The results of descriptive statistics related to the perceptions of the ten HumEnt components are presented in a graph along with the median (see Figure 1).

STUDY 2: Qualitative evidence of best practices. Sample. The selection of the enterprise was conditioned by a high level of HumEnt, which was measured based on the implementation of activities in the components of both the enterprise cycle and the human cycle. The main profile of the selected enterprise is production, and it operates on the global market. Employees of the company were subjected to the questionnaire survey in order to reproduce the actual state as credibly as possible, also from their perspective. The questionnaire was sent to employees, and the data were obtained from 47 respondents. In this part of the research, an in-depth interview was also conducted with the functional manager.

Results. A descriptive analysis was used to test the perceptions of HumEnt by employees. In this group, $80.9 \%$ were lower-level employees, and $19.1 \%$ were managers. The data was shown in a box plot (see Figure 2).

\begin{tabular}{|c|c|c|c|c|c|c|c|}
\hline \multirow[b]{2}{*}{ Business characteristics } & \multicolumn{2}{|c|}{$\begin{array}{c}\text { Up to } 49 \\
\text { employees }\end{array}$} & \multicolumn{2}{|c|}{$\begin{array}{c}\text { From } 50 \text { to } 249 \\
\text { employees }\end{array}$} & \multicolumn{2}{|c|}{$\begin{array}{l}\text { From } 249 \\
\text { employees }\end{array}$} & \\
\hline & $n$ & $\%$ & $n$ & $\%$ & $n$ & $\%$ & \\
\hline \multicolumn{8}{|l|}{ Main business profile } \\
\hline Production & 13 & 20.6 & 8 & 36.4 & 15 & 36.6 & \\
\hline Commercial & 12 & 19.0 & 2 & 9.1 & 8 & 19.5 & \\
\hline Service & 38 & 60.3 & 12 & 54.5 & 18 & 43.9 & \\
\hline Scale of activities & & & & & & & $\begin{array}{l}\text { Table } 2 . \\
\text { Characteristics of the }\end{array}$ \\
\hline Domestic markets & 49 & 77.8 & 5 & 22.7 & 11 & 26.8 & surveyed \\
\hline International markets & 14 & 22.2 & 17 & 77.3 & 30 & 73.2 & enterprises $(n=126)$ \\
\hline
\end{tabular}

\begin{tabular}{|c|c|c|c|c|c|c|c|}
\hline \multirow[b]{2}{*}{ Implementation/optimisation (in the last 2 years) } & \multicolumn{2}{|c|}{$\begin{array}{c}\text { Up to } 49 \\
\text { employees }\end{array}$} & \multicolumn{2}{|c|}{$\begin{array}{c}\text { From } 50 \text { to } \\
249 \\
\text { employees }\end{array}$} & \multicolumn{2}{|c|}{$\begin{array}{l}\text { From } 249 \\
\text { employees }\end{array}$} & \\
\hline & $n$ & $\%$ & $n$ & $\%$ & $n$ & $\%$ & \\
\hline Quality optimisation & 42 & 66.7 & 16 & 72.7 & 32 & 78.1 & Table \\
\hline Cost optimisation & 42 & 66.7 & 16 & 72.7 & 33 & 80.5 & Implementation of \\
\hline Process optimization & 21 & 34.3 & 16 & 72.7 & 30 & 73.2 & selected activities in \\
\hline Technology development & 27 & 42.9 & 14 & 63.6 & 27 & 65.9 & the surveyed \\
\hline New products/new markets & 50 & 79.4 & 21 & 95.5 & 36 & 87.8 & enterprises $(n=126)$ \\
\hline
\end{tabular}




\section{JSBED \\ 29,1}

Ethics

Engagement

Binary logistic regression based on enterprise size $(n=126)$

\begin{tabular}{|c|c|c|c|c|c|c|}
\hline Variables & $\begin{array}{l}\text { Size of } \\
\text { enterprise }\end{array}$ & Estimation & $p$-value & $\begin{array}{l}\text { Odds } \\
\text { ratio }\end{array}$ & $\begin{array}{c}\text { Confidence level } \\
\text { OR }-95 \%\end{array}$ & $\begin{array}{c}\text { Confidence leve } \\
\text { OR } 95 \% \\
\end{array}$ \\
\hline \multirow[t]{2}{*}{ Empowerment } & $\begin{array}{l}\text { From } 50 \text { to } 249 \\
\text { employees }\end{array}$ & 1.22 & 0.0456 & 3.38 & 1.02 & 11.13 \\
\hline & $\begin{array}{l}\text { Over } 249 \\
\text { employees }\end{array}$ & 1.48 & 0.0038 & 4.37 & 1.61 & 11.89 \\
\hline \multirow[t]{2}{*}{ Ethics } & $\begin{array}{l}\text { From } 50 \text { to } 249 \\
\text { employees }\end{array}$ & 1.74 & 0.0014 & 5.67 & 1.96 & 16.40 \\
\hline & $\begin{array}{l}\text { Over } 249 \\
\text { employees }\end{array}$ & 2.44 & $<0.0001$ & 11.42 & 4.48 & 29.12 \\
\hline \multirow[t]{2}{*}{ Equity } & $\begin{array}{l}\text { From } 50 \text { to } 249 \\
\text { employees }\end{array}$ & 0.81 & 0.1135 & 2.25 & 0.82 & 6.17 \\
\hline & $\begin{array}{l}\text { Over } 249 \\
\text { employees }\end{array}$ & 1.24 & 0.0034 & 3.46 & 1.51 & 7.93 \\
\hline \multirow[t]{2}{*}{ Engagement } & $\begin{array}{l}\text { From } 50 \text { to } 249 \\
\text { employees }\end{array}$ & 0.80 & 0.1297 & 2.22 & 0.79 & 6.20 \\
\hline & $\begin{array}{l}\text { Over } 249 \\
\text { employees }\end{array}$ & 1.61 & 0.0002 & 5.00 & 2.13 & 11.75 \\
\hline
\end{tabular}

\begin{tabular}{llccccc}
\hline Variables & Markets & Estimation & p-value & $\begin{array}{c}\text { Odds } \\
\text { ratio }\end{array}$ & $\begin{array}{c}\text { Confidence level } \\
\text { OR-95\% }\end{array}$ & $\begin{array}{c}\text { Confidence level } \\
\text { OR } 95 \%\end{array}$ \\
\hline Empowerment & International & 1.48 & 0.0008 & 4.37 & 1.85 & 10.35 \\
Ethics & International & 2.13 & 0.0000 & 8.41 & 3.71 & 19.09 \\
Equity & International & 1.50 & 0.0001 & 4.49 & 2.08 & 9.68 \\
Engagement & International & 1.43 & 0.0002 & 4.20 & 1.95 & 9.04 \\
Note(s): Modelling was set up for domestic markets & & & \\
\hline
\end{tabular}

\section{Table 5.}

Binary logistics regression based on markets $(n=126)$

Note(s): Modelling was set up for domestic markets

Spearman rank correlation matrix of variables

\begin{tabular}{lccccccccr} 
Variables & 1 & 2 & 3 & 4 & 5 & 6 & 7 & 8 & 9 \\
\hline 1. Empowerment & & & & & & & & & \\
2. Ethics & 0.777 & & & & & & & & \\
3. Equity & 0.618 & 0.733 & & & & & & & \\
4. Engagement & 0.739 & 0.741 & 0.665 & & & & & \\
5. Ecosystem & 0.553 & 0.633 & 0.717 & 0.627 & & & & \\
6. Envisioning & 0.559 & 0.453 & 0.467 & 0.575 & 0.595 & & & \\
7. Enthusiasm & 0.576 & 0.476 & 0.500 & 0.568 & 0.557 & 0.830 & & & \\
8. Experimentation & 0.463 & 0.404 & 0.418 & 0.510 & 0.438 & 0.736 & 0.732 & & \\
9. Enlightenment & 0.549 & 0.451 & 0.450 & 0.558 & 0.478 & 0.667 & 0.665 & 0.686 \\
10. Excellence & 0.570 & 0.492 & 0.487 & 0.577 & 0.507 & 0.630 & 0.601 & 0.594 & 0.787
\end{tabular}

The assessment of the actual state was carried out on the basis of specific activities in the scope of the indicated HumEnt components. The surveyed company indicates high activity supporting HumEnt by implementing new products and optimisation in terms of cost reduction, quality improvement and operational activities over the last year. The company 
has also developed new business opportunities in the last two years. The results are presented in Table 7.

The functional manager, when asked about how the company strives to increase empowerment among its employees, added:

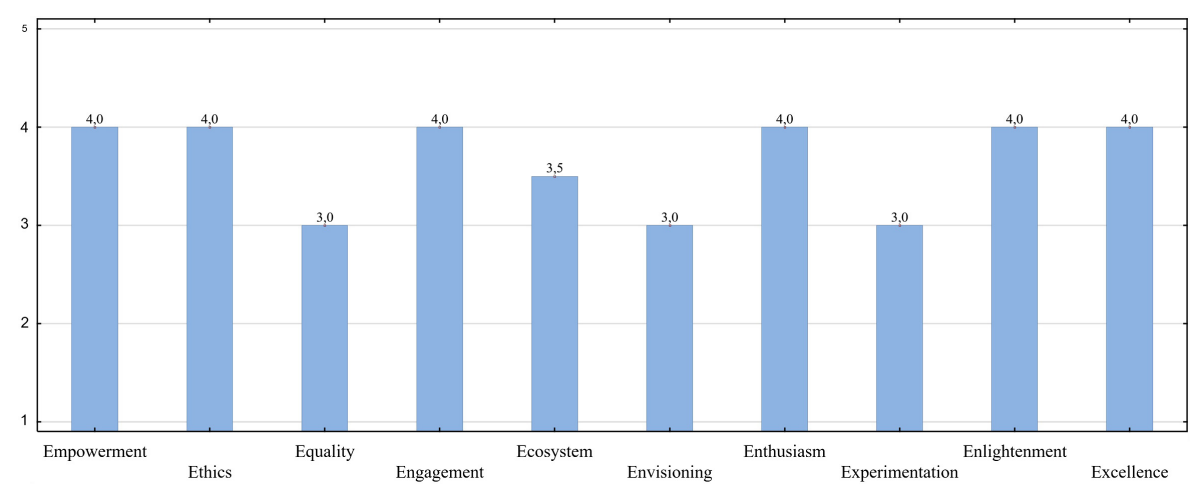

Median

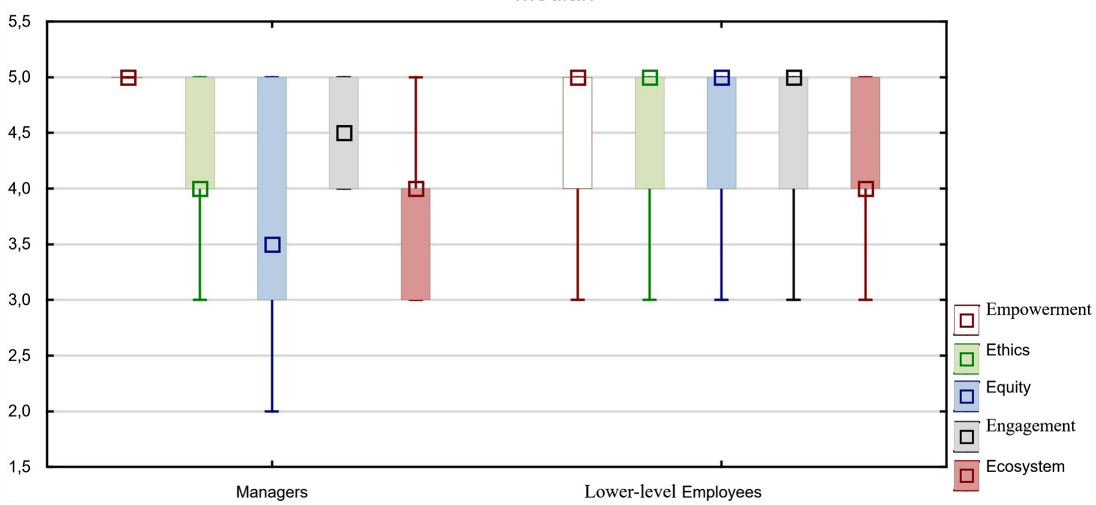

Humane entrepreneurship

Figure 1.

Perceptions of the ten HumEnt components

\section{Implementation of selected activities}

\section{Empowerment}

Ethics

Equity

Engagement

Envisioning

Enthusiasm

Enlightenment

Experimentation

Excellence

\section{Managers (\%)}

Lower-level employees (\%)

$\begin{array}{rr}100.0 & 97.4 \\ 33.3 & 39.5 \\ 88.9 & 79.0 \\ 66.7 & 76.3 \\ 88.9 & 76.3 \\ 100.0 & 89.5 \\ 88.9 & 76.3 \\ 100.0 & 89.5 \\ 88.9 & 76.3\end{array}$

Figure 2.

Perceptions of humane cycle by employees - a box plot
Table 7 The actual state of the surveyed enterprise from the perspective of employees $(n=47)$ 
JSBED

29,1

138

Managers, instead of directly delegating and managing employees, should share a broader vision and strategy of the company. Explaining "why", make it "what" and "how" remains in force employees. That is why, in our organisation, we continuously communicate 'company's strategy and regularly emphasis the company mission. This is our north star in setting local goals and objectives, witch to some extent, are set in collaborative way with employees during workshops. This way of working encourages employees to take action and focus on whole 'companies' performance, not only 'department's objectives. Goals set by employees became our facilities goal.

The manager also pointed out: "the company set priority to promote and support equity", and she referred to the company's goals that allow for a measurable assessment of the company's activity in this area: "We ensure that promotion decisions, training allocation are in line with the principles of equal employment opportunities. We implement this value through our diversity goals and measure progress."

Employees also have the opportunity to implement their ideas, as the manager claimed: "There are cross-functional projects where employees not only come up with ideas but also take responsibility for execution".

The in-depth interview allowed to capture good practices in the field of all the human cycle components, which are summarised in Table 8.

\section{Discussion}

The activities undertaken by the surveyed companies in the last two years indicate high entrepreneurial activity in the traditional sense. Most of the surveyed enterprises $(84.9 \%)$ developed new business opportunities (including new products, new markets and new types of business). A significant part of enterprises (69\%) implemented a new technological or

Components of the human

cycle

Best practices

Empowerment

Equality/equity

Engagement

Table 8.

Ecosystem

Qualitative evidence of best practices in the human cycle components practice times of crisis
Continuous communication of company strategy

Emphasising company mission

Setting collaborative goals through workshops

Encouraging employees to take action

Encouraging employees to focus on the whole company performance

Promoting high commitment to ethical behaviour

Launching the ethics and compliance office

Providing employees with support and guidance on how to act to ensure compliance with applicable laws

Providing a wide range of practical trainings to apply laws in day-to-day

Carrying out dilemma games

Promoting decision-making and trainings allocation in accordance with the principles of equal employment opportunity

Setting diversity goals

Measuring progress

Promoting engagement through collaboration and ownership

Implementing cross-functional projects where employees not only come up with ideas but also take responsibility for execution

Dedication and promoting results in the local organisation and beyond the teams Bringing value to local and national economies as well as generating a social and community-level impact

Supporting other entities with resources to meet global demand for products Supporting local communities in supplying hard-to-reach products, especially in 
process solution in the last year, and from the perspective of the last two years, the number of these enterprises increased to $92.8 \%$. Most of the surveyed enterprises $(71.4 \%)$ also indicated that they had made optimisation to reduce costs and improve the quality of their products or services in the last two years. The high activity of these companies in the field of enterprise cycle components may result from the period in which the research was conducted. Due to many socio-economic changes caused by COVID-19, enterprises had to try to adapt to the new conditions. Turbulent periods have been repeatedly presented in the literature as an impulse to act and implement new solutions (Seeger et al., 2003; Prewitt et al., 2011).

Human elements recognised by scholars are considered as factors that improve organisational performance by refocusing on people, reinforcing employee commitment and causing individuals to identify themselves more with the company as a whole. Moreover, in today's economic, political and global business ecosystem, the said components have become increasingly important and are considered by employees as a mandatory part of organisational culture, defining how the company listens to them at work (Deloitte, 2014). However, as indicated by scholars and practitioners and despite an increased emphasis on societal factors, businesses face a reality gap (Christensen et al., 2013), which is viewed as an organisation's ability to turn knowledge into action. Researchers highlight that the knowingdoing gap often results from a basic human propensity to want the conversation to replace action (Pfeffer and Sutton, 1999).

The presented study results show that the surveyed enterprises' perception of the importance of the selected HumEnt components is at a high level. The second study provided information on how important human aspects are, especially from the perspective of employees.

Nevertheless, not in every surveyed enterprise specific actions follow along with knowledge about the importance of human factors for the performance of their enterprise. The knowing-doing gap problem is especially visible in the smaller surveyed enterprises. Although more than half of the surveyed micro and small enterprises have a mission and vision $(57.3 \%)$, this mission is still unknown to over a third of employees $(36.1 \%)$. This phenomenon also occurs in larger companies which, despite declaring that they have a mission and vision $(85.4 \%)$, indicate that the majority of employees are not familiar with it $(51.4 \%)$. Further, the surveyed enterprises also indicated that they do not carry out any of (1) equity activities (60.3\%), (2) ethics activities (58.7\%) and (3) engagement activities $(61.2 \%)$. The surveyed medium and large enterprises indicated a relatively high degree of autonomy of their employees, while the small enterprises assessed the autonomy of their employees at a much lower level. These results refer to many studies on the characteristics of management and decision-making in SMEs, in which the decision-making process is usually described as centralised, concentrated mainly in the hands of one person - the owner-manager (Aspinwall and Yew Wong, 2004; Elkhairi et al., 2019; Ogarcă, 2010).

Based on the conducted research, we indicated that the micro and small enterprises much less frequently implement specific solutions that support the foundations of the HumEnt concept. Additionally, these differences can also be noticed in the context of the markets in which the surveyed companies operate.

Our proposal to capture the knowing-doing gap is shown in Figure 3.

Deloitte research shows that in order to address the phenomenon of an attitude-behaviour gap, organisations need, beyond training, to focus on measurement, transparency and personal accountability. Jackson et al. (2014) expand this statement by identifying core elements comprising an implementation system that includes: (1) overarching organisation philosophies, which clarify the values and corresponding behaviours; (2) formal policies, which are considered as an organisation's intent (3) day-to-day practices, which are the enactment of philosophies and policies, (4) processes through which values, policies, and practices are executed, modified, measured, and terminated (Schuler, 1992). 
JSBED

29,1

140

Figure 3.

Knowing-doing gap scheme

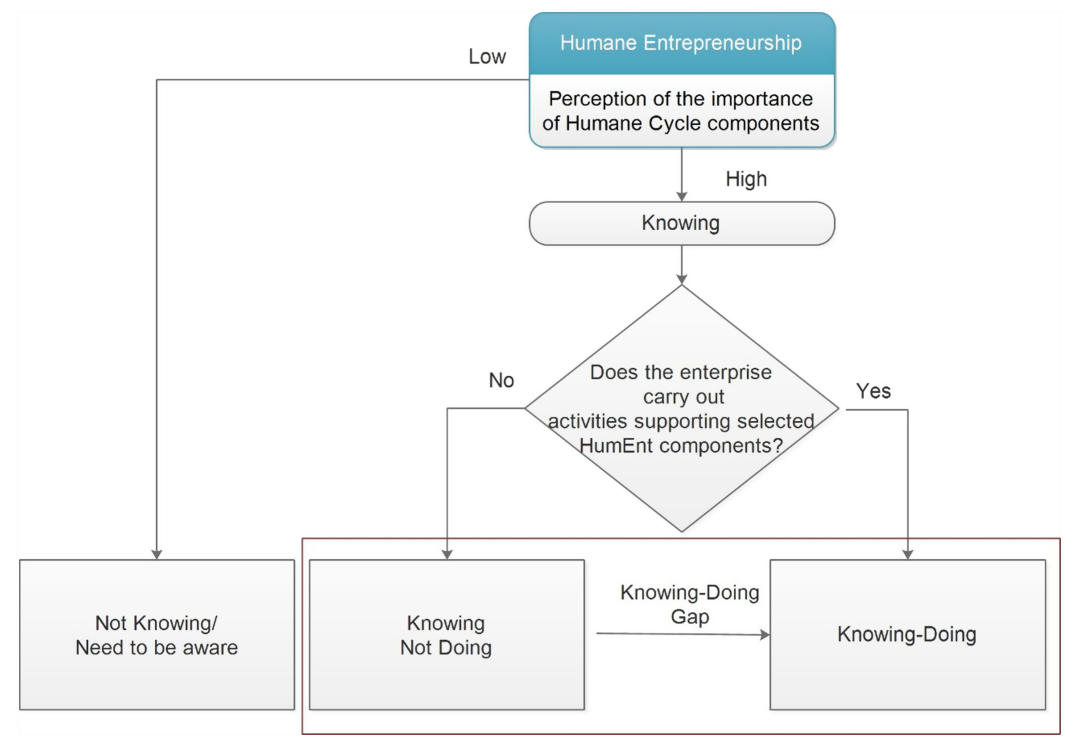

As noted in the second stage of our research, even companies that score high for human awareness may experience the knowing-doing gap. The differences are especially noticeable in the perception of human components in the case of managers. As one manager commented:

This gap shows us that we need to re-focus our efforts more on middle-management and make them aware how important human elements are for employees, how big impact those elements have on an organisation's performance and how important is their role and support in creating a workplace that delivers opportunity and fairness to everyone.

Research shows that there are many activities that an enterprise can do to support the human aspects of entrepreneurship. According to research, especially the smallest enterprises have a problem with the practical application of selected HumEnt components. As the surveyed manager indicates, they can also take actions for which the size of the enterprise and the resources held will not be an obstacle:

... in the large enterprises, it is mandatory to have in place a code of conduct, policies, and procedures to support diversity, equity, ecosystem, empowerment, and ethics. This is one of the simplest ways to work on mindset from the early beginning. Small companies can do it with no additional cost.

Along with the awareness of the need to consider the human factor in entrepreneurial activities, even the smallest enterprises should take action, starting with building an organisational culture. Therefore, it is possible to minimise the knowing-doing gap captured in the study.

\section{Implications, limitations and future research}

The development of the HumEnt concept is a response to the need to change business thinking in the context of the global achievement of SDGs. According to the concept of its creators, a new balance between enterprise cycles and human cycle is required. The enterprise cycle fits in with the traditional theory of entrepreneurship. The human cycle extends it to include employees, local communities and other stakeholders. Moreover, as 
Kim et al. (2018a) researched, sustainable HumEnt and a specific business system affect the GDP growth.

Therefore the purpose of our research was to examine, describe and discuss whether and to what extent elements of the HumEnt concept are executed in the economy practice by Polish enterprises. The study was multifaceted, and the achieved goals allowed to present the characteristics of enterprises in terms of specific activities undertaken in relation to HumEnt. We were also able to examine the perception of this concept among companies. In addition, thanks to an in-depth analysis of the selected company, we could compare these aspects between the company's management and lower-level employees. We also could identify specific actions supporting the company's humane resource orientation and sustainability orientation.

As our research results show, although the perception of the assumptions of the concept seems to be at a fairly high level, the implementation of activities stimulating the company's human cycle requires support. This can be a significant signal for business support institutions, in particular in terms of support for micro and small enterprises. As we showed in the study, these companies in particular, should be more oriented towards humane resources and elements of the humane cycle. Examples of activities in this area relate to the transfer of mission and vision, implementation of actions confirming the importance of equity, ethics, engagement and autonomy of employees. Additionally, we showed that there are differences in the perception of the concept depending on the level in the organisational structure. Enterprises should therefore undertake various activities supporting humane resource orientation, depending on the level of this structure. We have indicated numerous examples of such activities (Table 8), which in most cases can be successfully implemented also in small enterprises and do not require significant financial resources.

Our study, however, is not without limitations. The research sample did not allow for the generalisation of the results to the population of enterprises. In addition, due to the lack of developed measures of HumEnt at the time of conducting the research, we had to use an exploratory survey, which at this stage does not allow us to indicate the accurate HumEnt scale, but only allowed us to outline any activity in the studied areas.

Our goal was to investigate the phenomenon among enterprises in one of the regions of Poland. Nevertheless, it seems important to compare the activities undertaken by enterprises and their perceptions of concepts against the background of cultural, political and social differences in Europe. It can be assumed that these factors may also influence the implementation of HumEnt in practice.

Another aspect that requires examination is the identification of the differences between innovation-driven and efficiency-driven countries. The study by Song (2019) compared the perception of HumEnt in order to seize opportunities and a sustainable organisation among 19 countries. In order to measure HumEnt, ten components were used: empowerment, ethics, equality, commitment, ecosystem, imagination, enthusiasm, enlightenment, experimentation and excellence. The research results showed that the HumEnt outcome differed between the group of innovation-driven countries and the group of efficiency-driven countries. In the case of Korea, the indicators clearly dropped from the enterprise cycle to the human cycle. From the point of view of the HumEnt theory, a balance is needed between the human cycle and the enterprise cycle. We demonstrated the degree of implementation and the perception of individual components, in particular the human cycle of the HumEnt concept in the Polish economy that is an efficiency-driven economy. It would be interesting to check what differences exist between innovation-driven and efficiency-driven European countries in the next phase.

Next, it would be necessary to examine whether the organisational and legal form is related to the implementation of the concept. On the example of the study by Fernandez- 
JSBED

29,1

Guadano et al. (2020), which investigated differences between cooperatives and capitalist enterprises in achieving the goals of sustainable development in Spain, one can assume that there are some differences between enterprises of various legal forms in the implementation of the assumptions of the HumEnt theory. The study showed empirical evidence based on the stakeholder theory and on the differences between cooperatives and capitalist firms (CFs) in relation to the distribution of economic value between various stakeholders.

Capturing trends and changes over time that allow performing time-series analysis seems to be important, especially changes in the human cycle resulting from the effects of COVID-19. It should be assumed that these effects will be significant from the point of view of HumEnt.

Despite these limitations, the research results contribute to the discussion of HumEnt. They have a significant practical value and indicate specific activities and practices that can be successfully implemented, also in small and medium-sized enterprises. They can be a source of information and an impulse for business practice, especially during the COVID-19 pandemic.

\section{References}

Aguinis, H., Villamor, I. and Gabriel, K.P. (2020), "Understanding employee responses to COVID-19: a behavioral corporate social responsibility perspective", Management Research, Vol. 18 No. 4, pp. 421-438, doi: 10.1108/MRJIAM-06-2020-1053.

Bae, Z.-T., Kang, M.S., Kim, K.C. and Park, J.H. (2018), "Humane entrepreneurship: theoretical foundations and conceptual development", The Journal of Small Business Innovation, Vol. 20 No. 4, pp. 11-21.

Bakker, A.B. (2011), "An evidence-based model of work engagement”, Current Directions in Psychological Science, Vol. 20 No. 4, pp. 265-269, doi: 10.1177/0963721411414534.

Bartsch, S., Weber, E., Büttgen, M. and Huber, A. (2020), "Leadership matters in crisis-induced digital transformation: how to lead service employees effectively during the COVID-19 pandemic", Journal of Service Management, Vol. 32 No. 1, pp. 71-85, doi: 10.1108/JOSM-05-2020-0160.

Belz, F.M. and Binder, J.K. (2017), "Sustainable entrepreneurship: a convergent process model", Business Strategy and the Environment, Vol. 26 No. 1, pp. 1-17, doi: 10.1002/bse.1887.

Blanchard, W. (1986), "Evaluating social equity: what does fairness mean and can we measure it?", Policy Studies Journal, Vol. 15 No. 1, pp. 29-54, doi: 10.1111/j.1541-0072.1986.tb00442.x.

Bland, J.M. and Altman, D.G. (1997), "Statistics notes: cronbach's alpha”, BMJ, Vol. 314 No. 7080, p. 572.

Braverman, B. (2020), The Coronavirus Is Taking a Huge Toll on Workers' Mental Health across America, CNBC, 2020 April 6 , available at: https://www.cnbc.com/2020/04/06/coronavirus-istaking-a-toll-on-workers-mental-health-across-america.html (accessed 20 January 2021).

Brown, M.E., Treviño, L.K. and Harrison, D.A. (2005), "Ethical leadership: a social learning perspective for construct development and testing", Organizational Behavior and Human Decision Processes, Vol. 97 No. 2, pp. 117-134, doi: 10.1016/j.obhdp.2005.03.002.

Chanana, N. (2020), "Employee engagement practices during COVID-19 lockdown", Journal of Public Affairs, e2508, doi: 10.1002/pa.2508.

Christensen, L.T., Morsing, M. and Thyssen, O. (2013), "CSR as aspirational talk", Organization, Vol. 20 No. 3, pp. 372-393, doi: 10.1177/1350508413478310.

Couper, M. (2000), "Web surveys: a review of issues and approaches", Public Opinion Quarterly, Vol. 64 No. 4, pp. 464-494, doi: 10.1086/318641.

Covin, J.G. and Slevin, D.P. (1989), "Strategic management of small firms in hostile and benign environments", Strategic Management Journal, Vol. 10 No. 1, pp. 75-87, doi: 10.1002/smj. 4250100107. 
Csikszentmihalyi, M. (1990), Flow: the Psychology of Optimal Experience, 1st ed., Harper \& Row, New York.

Di Leo, G. and Sardanelli, F. (2020), "Statistical significance: p value, 0.05 threshold, and applications to radiomics-reasons for a conservative approach", European Radiology Experimental, Vol. 4 No. 1, p. 18, doi: 10.1186/s41747-020-0145-y.

Deloitte (2014), "The Deloitte Millennial Survey. Big demands and high expectations", available at: https:/www2.deloitte.com/content/dam/Deloitte/global/Documents/About-Deloitte/gx-dttl-2014millennial-survey-report.pdf (accessed 20 January 2021).

Donald, I., Taylor, P., Johnson, S., Cooper, C., Cartwright, S. and Robertson, S. (2005), "Work environments, stress, and productivity: an examination using ASSET", International Journal of Stress Management, Vol. 12 No. 4, pp. 409-423, doi: 10.1037/1072-5245.12.4.409.

Ebert, J.F., Huibers, L., Christensen, B. and Christensen, M.B. (2018), "Paper- or web-based questionnaire invitations as a method for data collection: cross-sectional comparative study of differences in response rate, completeness of data, and financial cost", Journal of Medical Internet Research, Vol. 20 No. 1, p. e24, doi: 10.2196/jmir.8353.

EC Recommendation (2003), "Commission recommendation of 6 May 2003 concerning the definition of micro, small and medium-sized enterprises", available at: https:/op.europa.eu/pl/publicationdetail/-/publication/6ca8d655-126b-4a42-ada4-e9058fa45155/language-en (accessed 20 January 2021).

Eisenbeiß, S.A. and Giessner, S.R. (2012), "The emergence and maintenance of ethical leadership in organisations", Journal of Personnel Psychology, Vol. 11 No. 1, pp. 7-19, doi: 10.1027/1866-5888/ a000055.

Elkhairi, A., Fedouaki, F. and Alami, S.E. (2019), "Barriers and critical success factors for implementing lean manufacturing in SMEs", IFAC-PapersOnLine, Vol. 52 No. 13, pp. 565-570, doi: 10.1016/j.ifacol.2019.11.303.

Fernandez-Guadaño, J., Lopez-Millan, M. and Sarria-Pedroza, J. (2020), “Cooperative entrepreneurship model for sustainable development”, Sustainability, Vol. 12 No. 13, p. 5462, doi: 10.3390/ su12135462.

Gusmão Caiado, R.G., Leal Filho, W., Quelhas, O.L.G., Luiz de Mattos Nascimento, D. and Ávila, L.V. (2018), "A literature-based review on potentials and constraints in the implementation of the sustainable development goals”, Journal of Cleaner Production, Vol. 198, pp. 1276-1288, doi: 10. 1016/j.jclepro.2018.07.102.

Harter, J.K., Schmidt, F.L. and Hayes, T.L. (2002), "Business-unit-level relationship between employee satisfaction, employee engagement, and business outcomes: a meta-analysis", The Journal of Applied Psychology, Vol. 87 No. 2, pp. 268-279, doi: 10.1037/0021-9010.87.2.268.

Jackson, S.E., Schuler, R.S. and Jiang, K. (2014), "An aspirational framework for strategic human resource management”, The Academy of Management Annals, Vol. 8 No. 1, pp. 1-56, doi: 10. 1080/19416520.2014.872335.

Jex, S. and Britt, T.W. (2008), Organizational Psychology: A Scientist-Practitioner Approach, 2nd ed., Wiley, Hoboken, NJ.

Kim, R.C. (2018), "Can Creating Shared Value (CSV) and the United Nations Sustainable Development Goals (UN SDGs) collaborate for a better world? Insights from East Asia”, Sustainability, Vol. 10 No. 11, p. 4128, doi: 10.3390/su10114128.

Kim, K.C., ElTarabishy, A. and Bae, Z.T. (2018a), "Humane entrepreneurship: how focusing on people can drive a new era of wealth and quality job creation in a sustainable world", Journal of Small Business Management, Vol. 56, pp. 10-29, doi: 10.1111/jsbm.12431.

Kim, K.C., Hornsby, J.S., Enriquez, J.L., Bae, Z.T. and El Tarabishy, A. (2021), "Humane entrepreneurial framework: a model for effective corporate entrepreneurship", Journal of Small Business Management, Vol. 59 No. 3, pp. 397-416, doi: 10.1080/00472778.2021. 1896723. 
JSBED

29,1

Kiyabo, K. and Isaga, N. (2020), "Entrepreneurial orientation, competitive advantage, and 'SMEs' performance: application of firm growth and personal wealth measures", Journal of Innovation and Entrepreneurship, Vol. 9 No. 1, doi: 10.1186/s13731-020-00123-7.

Kumar, P. (2021), "V-5 model of employee engagement during COVID-19 and post lockdown", Vision, Vol. 25 No. 3, doi: 10.1177/0972262920980878.

Lakens, D. (2021), "The practical alternative to the $\mathrm{p}$ value is the correctly used $\mathrm{p}$ value", Perspectives on Psychological Science, Vol. 16 No. 3, pp. 639-648, doi: 10.1177/1745691620958012.

Larkin, J. and Staton, P. (2001), "Access, inclusion, climate, empowerment (AICE): a framework for gender equity in market-driven education", Canadian Journal of Education/Revue canadienne de l'éducation, Vol. 26 No. 3, p. 361, doi: 10.2307/1602213.

Lumpkin, G.T. and Dess, G.G. (1996), "Clarifying the entrepreneurial orientation construct and linking it to performance", The Academy of Management Review, Vol. 21 No. 1, p. 135, doi: 10.2307/ 258632.

Maula, M. and Wouter, S., "Enhancing rigor in quantitative entrepreneurship research", Entrepreneurship Theory and Practice, Vol. 44 No. 6, pp. 1059-1090, doi: 10.1177/ 1042258719891388.

Maxwell, J.A. and Chmiel, M. (2014), "Generalisation in and from qualitative analysis", in Flick, U. (Ed.), The Sage Handbook of Qualitative Data analysis., Generalisation in and from Qualitative Analysis, SAGE Publications.

Maxwell, J.A. (2010), "Using numbers in qualitative research", Qualitative Inquiry, Vol. 16 No. 6, pp. 475-482, doi: 10.1177/1077800410364740.

McWilliams, A. and Siegel, D. (2001), "Corporate social responsibility: a theory of the firm perspective", The Academy of Management Review, Vol. 26 No. 1, p. 117, doi: 10.2307/259398.

Menon, S. (2001), "Employee empowerment: an integrative psychological approach", Applied Psychology, Vol. 50 No. 1, pp. 153-180, doi: 10.1111/1464-0597.00052.

Miller, D. (1983), "The correlates of entrepreneurship in three types of firms", Management Science, Vol. 29 No. 7, pp. 770-791, doi: 10.1287/mnsc.29.7.770.

Mühlbacher, H. and Böbel, I. (2019), "From zero-sum to win-win - organisational conditions for successful shared value strategy implementation”, European Management Journal, Vol. 37 No. 3, pp. 313-324, doi: 10.1016/j.emj.2018.10.007.

Ntona, M. and Morgera, E. (2018), "Connecting SDG 14 with the other sustainable development goals through marine spatial planning", Marine Policy, Vol. 93, pp. 214-222, doi: 10.1016/j.marpol. 2017.06.020.

Ogarcă, R. (2010), "Features of the decision-making IN SMES", Annals of the University of Craiova, Economic Sciences Series, Vol. 3 No. 38, pp. 1-20.

Parente, R. and Kim, K.C. (2021), "Editorial: contemporary perspectives on social and humane entrepreneurship", Journal of Small Business Management, Vol. 59 No. 3, pp. 371-372, doi: 10. 1080/00472778.2021.1896724.

Parente, R., El Tarabishy, A., Vesci, M. and Botti, A. (2018), "The epistemology of humane entrepreneurship: theory and proposal for future research agenda", Journal of Small Business Management, Vol. 56 No. S1, pp. 30-52.

Parente, R., El Tarabishy, A., Botti, A., Vesci, M. and Feola, R. (2020), "Humane entrepreneurship: some steps in the development of a measurement scale", Journal of Small Business Management, Vol. 59 No. 3, pp. 1-25, doi: 10.1080/00472778.2020.1717292.

Park, K.O. (2020), "How CSV and CSR affect organisational performance: a productive behavior perspective", International Journal of Environmental Research and Public Health, Vol. 17 No. 7 , doi: 10.3390/ijerph17072556.

Pfeffer, J. and Jeffrey, P. (1998), The Human Equation: Building Profits by Putting People First, Harvard Business Press, Boston. 
Pfeffer, J. and Sutton, R.I. (1999), "The smart-talk trap”, Harvard Business Review, Vol. 77 No. 3, pp. 134-142, 211. PMID: 10387575.

Porter, M.E. and Kramer, M.R. (2011), "The big idea creating shared value”, Harvard Business Review, Vol. 89, pp. 2-17.

Prewitt, J.E., Weil, R. and McClure, A.Q. (2011), "Crisis leadership-an organisational opportunity", Australian Journal of Business and Management Research, Vol. 1 No. 6, p. 60.

Recuero Virto, L. (2018), "A preliminary assessment of the indicators for sustainable development goal (SDG) 14 conserve and sustainably use the oceans, seas and marine resources for sustainable development”, Marine Policy, Vol. 98, pp. 47-57, doi: 10.1016/j.marpol.2018.08.036.

Rosati, F. and Faria, L.G.D. (2019), "Business contribution to the sustainable development agenda: organisational factors related to early adoption of SDG reporting", Corporate Social Responsibility and Environmental Management, Vol. 26 No. 3, pp. 588-597, doi: 10.1002/csr.1705.

Schaufeli, W.B. and Bakker, A.B. (2010), "The conceptualisation and measurement of work engagement", in Bakker, A.B. and Leiter, M.P. (Eds), Work Engagement: A Handbook of Essential Theory and Research, Psychology Press, New York, pp. 10-24.

Schuler, R.S. (1992), "Strategic human resources management: linking the people with the strategic needs of the business", Organizational Dynamics, Vol. 21 No. 1, pp. 18-32, doi: 10.1016/00902616(92)90083-Y.

Seeger, M.W., Sellnow, T.L. and Ulmer, R.R. (2003), Communication and Organisational Crisis, Greenwood Publishing Group, Westport.

Song, C. (2019), "Humane entrepreneurship and strategies for countries by performance and economic development", The Korean Academic Association of Business Administration, Vol. 32 No. 2, pp. 219-235, doi: 10.18032/kaaba.2019.32.2.219.

Statistics Poland (2020), "Information society in Poland in 2020", available at: https:/stat.gov.p1/ download/gfx/portalinformacyjny/pl/defaultaktualnosci/5497/1/14/1/spoleczenstwo_ informacyjne_w_polsce_w_2020_r.pdf (accessed 15 Agust 2021).

Strike, K.A. (1985), "Is there a conflict between equity and excellence"?", Educational Evaluation and Policy Analysis, Vol. 7 No. 4, pp. 409-416, doi: 10.3102/01623737007004409.

Sussan, F. and Acs, Z.J. (2017), "The digital entrepreneurial ecosystem", Small Business Economics, Vol. 49 No. 1, pp. 55-73, doi: 10.1007/s11187-017-9867-5.

Szabowska-Walaszczyk, A., Zawadzka, A.M. and Brzozowski, A.S. (2013), "Employee engagement: how business goals can be achieved through employee well-being, conference paper scientific management and management science today", International Scientific Conference at: Szeged, Hungary.

Tuzovic, S. and Kabadayi, S. (2020), "The influence of social distancing on employee well-being: a conceptual framework and research agenda", Journal of Service Management, Vol. 32 No. 2, doi: 10.1108/JOSM-05-2020-0140.

UN General Assembly (2015), "Resolution adopted by the general assembly on 25 September 2015, A/RES/70/1", (21 October 2015). (The New York Declaration), available at: https://www.un.org/ ga/search/view_doc.asp?symbol=A/RES/70/1\&Lang =E (accessed 20 January 2021).

US International Trade Commission (2010), Small and Medium-Sized Enterprises: Characteristics and Performance, Investigation No. 332-510, available at: https://www.usitc.gov/publications/332/ pub4189.pdf (accessed 28 August 2021).

White Book (2016), "Humane entrepreneurship", available at: https://docs.wixstatic.com/ugd/cc1725_ c642180108094a59b1c53bb81a8b6d2b.pdf (accessed 20 January 2021).

Yew Wong, K. and Aspinwall, E. (2004), "Characterising knowledge management in the small business environment”, Journal of Knowledge Management, Vol. 8 No. 3, pp. 44-61, doi: 10.1108/ 13673270410541033.

\section{Humane entrepreneur- ship}


JSBED

29,1

\section{Further reading}

Bastida, M., Vaquero García, A., Cancelo Márquez, M. and Olveira Blanco, A. (2020a), "Fostering the sustainable development goals from an ecosystem conducive to the SE: the Galician's case", Sustainability, Vol. 12 No. 2, p. 500, doi: 10.3390/su12020500.

Bastida, M., Vaquero García, A., Cancelo Márquez, M. and Olveira Blanco, A. (2020b), "Fostering the sustainable development goals from an ecosystem conducive to the SE: the Galician's case", Sustainability, Vol. 12 No. 500, pp. 1-17, doi: 10.3390/su12020500.

Bijman, J. (2018), "Exploring the sustainability of the cooperative model in dairy: the case of The Netherlands", Sustainability, Vol. 10 No. 7, p. 2498, doi: 10.3390/su10072498.

Guzman, C., Santos, F.J. and Barroso, M.D. (2019), "Cooperative essence and entrepreneurial quality: a comparative contextual analysis", Annals of Public and Cooperative Economics, Vol. 91, pp. 95-118, doi: 10.1111/apce.12257.

Jex, S.M. (2014), Organizational Psychology [Electronic Resource]: A Scientist-Practitioner Approach, 3rd ed., Wiley, Hoboken, New Jersey.

Khurana, I., Ghura, A.S. and Dutta, D.K. (2021), "The influence of religion on the humane orientation of entrepreneurs", Journal of Small Business Management, Vol. 59 No. 3, pp. 417-442, doi: 10.1080/ 00472778.2021.1890097.

Kim, Y.J., Kim, K.C., Song, C.S. and Kang, M.S. (2018b), "The impact of humane entrepreneurship on business ecosystem and economic development", in ICSB World Conference Proceedings, International Council for Small Business (ICSB), pp. 1-8.

Mozas-Moral, A. and Puente-Poyatos, R. (2010), "Corporate social responsibility and its parallelism with cooperative societies", REVESCO Revista de Estud Cooperation, Vol. 103, pp. 75-100.

Pérez-Sanz, F.J., Gargallo-Castel, A.F. and Esteban-Salvador, M.L. (2019), "CSR practices among Cooperatives. Experience and results of case studies”, Ciriec España Revista de Economía Pública Social y Cooperative, Vol. 97, pp. 137-178.

\section{Corresponding author}

Anna Dębicka can be contacted at: anna.debicka@put.poznan.pl

For instructions on how to order reprints of this article, please visit our website:

www.emeraldgrouppublishing.com/licensing/reprints.htm

Or contact us for further details: permissions@emeraldinsight.com 